\title{
Effect of Natural Aging and Fatigue Crack Propagation Rate on Welded and Non-Welded Aluminum Alloy (AA2219-T87)
}

\author{
Mudasir ljaz', Faisal Qayyum², Hassan Elahi i, ${ }^{3}$, Mudaser Ullah ${ }^{4}$, \\ Marco Eugeni ${ }^{3}$, Saeed Badshah', Paolo Gaudenzi ${ }^{3}$ \\ 1 Department of Mechanical Engineering, International Islamic University, Islamabad, Pakistan \\ 2 Institut für Metallformung, TU Bergakademie Freiberg, Bernhard-von-Cotta-Strasse 4, 09599 Freiberg \\ (Sachsen), Germany \\ 3 Department of Mechanical and Aerospace Engineering, Sapienza University of Rome, Rome 00186, Italy \\ 4 Department of Mechanical Engineering, University College of Engineering and Technology, University of \\ Sargodha, Pakistan \\ * Corresponding author's e-mail: hassan.elahi@uniroma1.it
}

\begin{abstract}
Aluminum alloys are widely used for fabrication of aircraft, civil structures, and space vehicles. Fatigue life consideration of a material is the most important design criteria in many such critical applications. In this research work, a widely used Aluminum alloy AA2219-T87 was TIG welded using AA2319 as a filler material. The effect of natural aging on Fatigue Crack Propagation Rate (FCPR) of welded and non-welded compact tension (CT) specimens (AA2219-T87) is studied. The relationship between stress intensity factor $(\Delta \mathrm{K})$ and crack ratio $(\mathrm{a} / \mathrm{W})$ for different value of the crack length in base metal and the welded zone is presented. Paris curves for both welded and non-welded specimens and compared to study the effect of natural aging (NA) on FCGR and compared with non-aged specimens. The results obtained provide a base for the development of Structural Health Monitoring systems for the propagation of crack growth in such components.
\end{abstract}

Keywords: natural aging; AA2219; crack growth rate; structure health; fatigue; microstructure; stress intensity factor

\section{INTRODUCTION}

Among the heat treatable 2XXX series (according to Aluminium Association of USA). Al alloys, AA 2219 has a great potential for a wide range of applications owing to their high specific strength, good fracture toughness and excellent stress corrosion resistance [1-3]. The components undergo cyclic mechanical and thermal loading and hence are prone to fatigue failure. Therefore, it is essential to estimate the fatigue life of such critical components. To avoid unexpected failure, a comprehensive study of fatigue failure analysis has been carried out by several researchers in the past [4-7].
Generally, the manufacturing of components requires some joining process i.e. welding. It has been previously shown that TIG welding is the most suitable joining process for Aluminum components [8]. During TIG welding of Aluminum plates, its large amount of heat is produced which dissipates into base material during cooling [9]. This heating of weld zone and its surroundings to very high-temperature results in a drastically changing microstructure. It has been reported in the literature from time to time that in spite of good weldability, the impact toughness and fracture toughness of weld area is always less as compared to base metal $[10,11]$. To reduce the effects of residual stresses and non-homogeneous 
microstructure in the welded components they are heat treated. It was studied earlier that normalizing heat treatment of welded components significantly helped in homogenizing the microstructure in different weld zones and hence in the improvement of the mechanical and fatigue strength of these zones [12].

It has been reported that Aluminum alloys being less dense undergo natural aging at room temperature [13]. Although this phenomenon is very slow at room temperature, yet, a significant change in the microstructure was observed for AA2219 material when kept for 12 hours at $175^{\circ} \mathrm{C}$. Considering the variation in grain size, chemistry, precipitates size and morphology in different weld zones, it is expected that they will undergo different aging routes and hence the mechanical properties of different zones will not be similar after aging [14]. The aging of aluminum alloys due to its general high density is very slow therefore to study this effect, scientists use artificial aging technique [15] in which the sample is heated and kept at $163^{\circ} \mathrm{C}$ for 24 hours time and then cooled [16].

After extensive study researchers have concluded that the main effect of natural aging on the mechanical properties of $\mathrm{Al}-\mathrm{Mg}-\mathrm{Si}-\mathrm{Cu}$ alloy (AA6111) is due to the motion of precipitates and variation in dislocation density of the material inside grains and at grain boundaries. It was shown that aging reversed the formation of $\beta$-phase which is the main strengthening phase in Aluminum alloys [17]. Many researchers have also examined the natural aging effect on the hardening behavior of Aluminum alloys Al-Mg-Si by introducing aging in different and multi-stages. The results indicated that clusters/GP zones forming during natural aging could reduce the rate of hardening during subsequent multistage aging and the influence was more distinct during overaging [18]. It is also observed that during aging of such alloys, the alloying elements and small precipitates segregate on the grain boundaries which on one hand reduce the strength of grains and on the other hand, make the already dislocation density rich grain boundaries more coarse and brittle [19], which fail earlier due to applied monotonic or fatigue load when compared with non-aged alloys.
Very few studies have dealt with the effect of microstructural variations and their effect on the life of components [20-29]. This lack of understanding highly limits the life assessment of Aluminum alloys such as AA2219 when used in aircraft and automotive application and requires fatigue damage tolerance to be considered during the designing of such components [30-32]. This research deals with the evolution of microstructural changes and their effect on the fatigue life due to the natural aging of the Al6061 base metal and weld nugget zones. The study is targeted to provide researchers and designers with an accurate idea of variance in microstructural attributes of different weld zones and fatigue strength of components before and after 3 years of natural aging of Al6061 alloy. The research carried out enhances our understanding and paves the path for the development of better assessment of fatigue damage tolerance and hence develop better structural health monitoring models by considering the effect of aging.

\section{MATERIALS AND METHODS}

\section{Material}

In this research, the fatigue crack propagation behavior in naturally aged TIG welded and nonwelded aluminum alloy AA2219-T87 specimen has been studied. It is a wrought aluminum alloy with copper as the main constituent. AA2319 has been used as a filler material.

The chemical composition of base material and filler are presented in Table I [2]. TIG Welding parameters are presented in Table II.

\section{Experimental Procedure}

FCGR investigations were carried out for welded and non-welded specimens. The specimens were cut from $4 \mathrm{~mm}$ thick plate with the help of wire cut machine and notches were made on the EDM machine using a special electrode. The performed tests were tension-tension. Test parameters are shown in Table III. Tensile and high-tension fatigue tests were performed on

Table 1. Chemical composition of AA2219

\begin{tabular}{|c|c|c|c|c|c|c|c|c|c|c|}
\hline Material & $\mathrm{Al}$ & $\mathrm{Si}$ & $\mathrm{V}$ & $\mathrm{Cu}$ & $\mathrm{Mn}$ & $\mathrm{Mg}$ & $\mathrm{Zr}$ & $\mathrm{Ti}$ & $\mathrm{Fe}$ & $\mathrm{Zn}$ \\
\hline $\mathrm{AA2219}$ & $\mathrm{Bal}$. & 0.2 & 0.04 & 6.3 & 0.3 & 0.02 & 0.18 & 0.06 & 0.23 & 0.04 \\
\hline AA2319 & Bal. & 0.2 & 0.10 & 5.8 & 0.3 & 0.03 & 0.15 & 0.15 & 0.30 & 0.18 \\
\hline
\end{tabular}


MTS 810 with a maximum load of $1.7 \mathrm{kN}$ having a stress ratio of 0.1 and a frequency of $10 \mathrm{~Hz}$. The data of applied force vs crack propagation was acquired on MTS database system and them later mathematically processed to obtain crack mouth opening and stress intensity factors.

Crack mouth opening displacement (CMOD) were measured using CMOD gauge on MTS. Three tests for both welded and non-welded specimens were performed. From the value of stress applied, was ensured that the test conditions abide by the linear elastic fracture mechanics (LEFM) conditions.

\section{Optical Microscopy}

The metallography of naturally aged, welded and the non-welded specimen was investigated using a metallurgical microscope (Olympus D20). The finally polished specimens were etched using Keller's regent, (5ml HNO3 (conc.), $2 \mathrm{ml} \mathrm{HF} \mathrm{(48 \%} \mathrm{conc.),} 3 \mathrm{ml} \mathrm{HCL} \mathrm{(conc.)} \mathrm{and} 90 \mathrm{ml}$ distilled $\left(\mathrm{H}_{2} \mathrm{O}\right)$ ). The microstructure of specimens was investigated at different zones i.e. base metal (BM), heat affected zone (HAZ) and weldnugget zone (WNZ).

TESCAN VEGA 3 Scanning Electron Microscope (SEM) was used to study the microstructure of samples after aging at higher magnifications.
Table 2. Welding parameters

\begin{tabular}{|l|c|}
\hline Welding Voltage & $35 \mathrm{~V}$ \\
\hline Welding Speed & $1-1.7 \mathrm{~mm} / \mathrm{sec}$ \\
\hline Welding Current & $200 \mathrm{~A}$ \\
\hline Argon Purity & $99.9 \%$ \\
\hline Gas Flow Rate & $14 \mathrm{~L} / \mathrm{min}$ \\
\hline
\end{tabular}

Table 3. MTS testing parameters

\begin{tabular}{|l|c|}
\hline Maximum Load & $1.7 \mathrm{kN}$ \\
\hline Load Ratio, R & 0.1 \\
\hline Testing Frequency & $10 \mathrm{~Hz}$ \\
\hline Temperature & $25 \mathrm{of}$ \\
\hline
\end{tabular}

\section{Determination of FCGR Curves (Paris Curves)}

Fatigue test parameters testing parameters of MTS have been given in Table III. Curves of Fatigue Crack Growth Rate (FCGR) for both aged and non-aged and welded and non-welded AA2219 alloys are plotted. The testing parameter i.e. load ratio (R) and others are kept the same for both types of CT specimens. For testing, frequency is kept $10 \mathrm{~Hz}$ and the load ratio (R) is 0.1 . It is not possible to take the optical readings at $10 \mathrm{~Hz}$ so for readings; frequency was reduced to $1 \mathrm{~Hz}$.

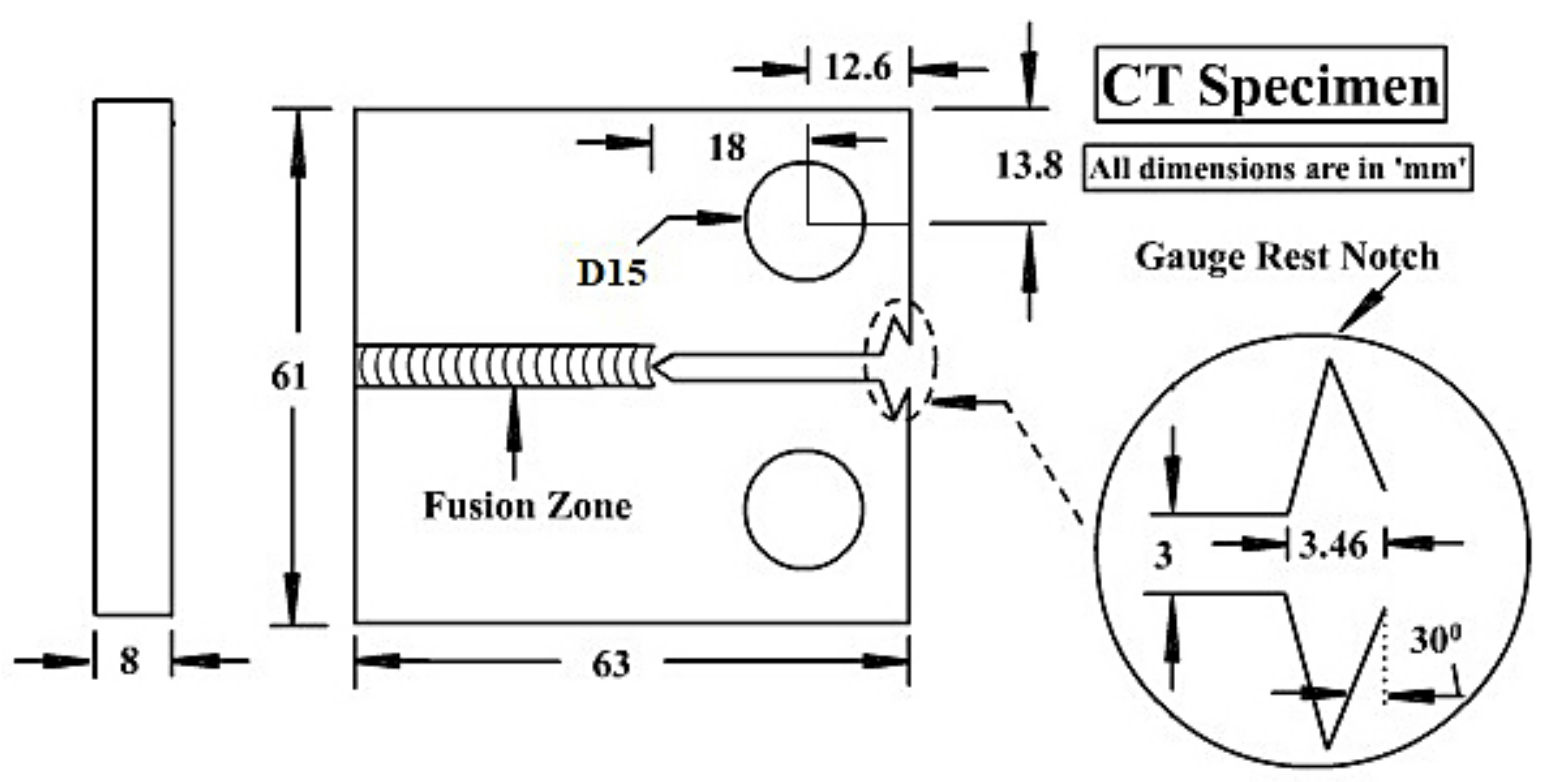

Fig. 1. Specimen dimensions and details of the notch. a) Base metal b) Orientation of weld in the specimen 


\section{RESULTS}

\section{Relation between $\mathrm{f}(\mathrm{a} / \mathrm{w})$ and a/w before $\&$ after aging}

\section{Base Metal}

The $\mathrm{f}(\mathrm{a} / \mathrm{w})$ is called the geometric correction factor. Its relation is determined with respect to the ratio between crack length " $a$ " and specimen width " $w$ ". The correction factor is calculated from the formulae of the stress intensity factor [33].

$$
\mathrm{K} 1=\sigma \sqrt{\pi \mathrm{a}} \cdot \mathrm{f}\left(\frac{\mathrm{a}}{\mathrm{w}}\right)
$$

From Figure 2 it is elaborated that there is a linear relation between geometric correction factor and ratio of crack length to specimen width. The linear relation in Figure 2 also depicts the uniformity in the material microstructure.
However, after the natural aging, for the sake of extra care and results accuracy, geometric factor effects are verified in Figures 3 and 4. From the below mentioned Figure 2, it is evident that for base metal, the geometric effects are almost equivalent to zero. The slope of the line is almost the same in aged and non-aged base metal.

\section{WeldNugget Zone}

It is observed that the geometric correction factor behavior with respect to crack length to specimen width ratio of welded specimens before aging is not same as for the base metal which depicts that some structural changes take place after welding. From the previous test results of without natural aging, it can be concluded that initially there is a linear relation between geometric correction factor and $\mathrm{a} / \mathrm{W}$. The slope of the curve is low at the beginning but then increases and is similar for the welded and non-welded samples as shown in Figure 5.

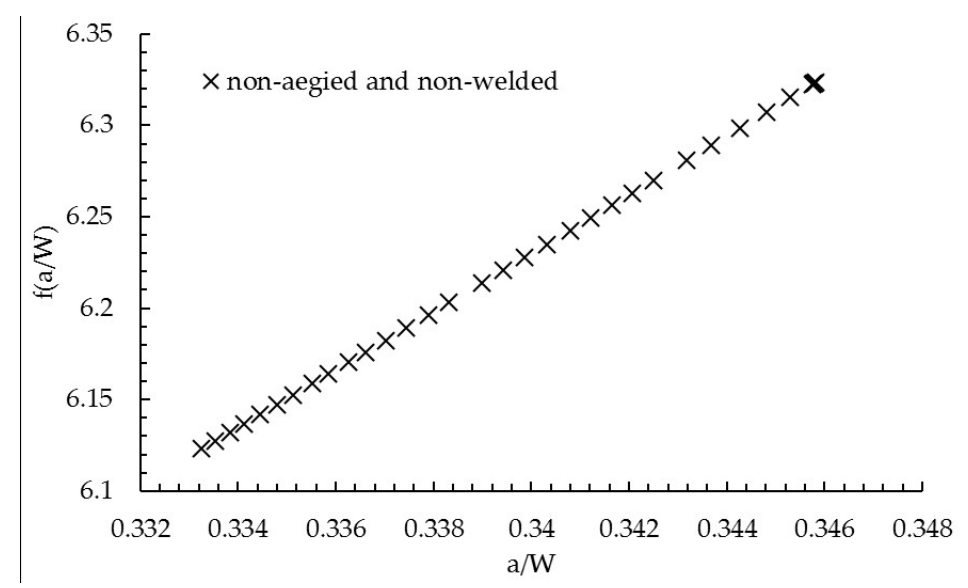

Fig. 2. Relation between $\mathrm{f}(\mathrm{a} / \mathrm{w})$ and $\mathrm{a} / \mathrm{w}$ for non-welded CT specimen

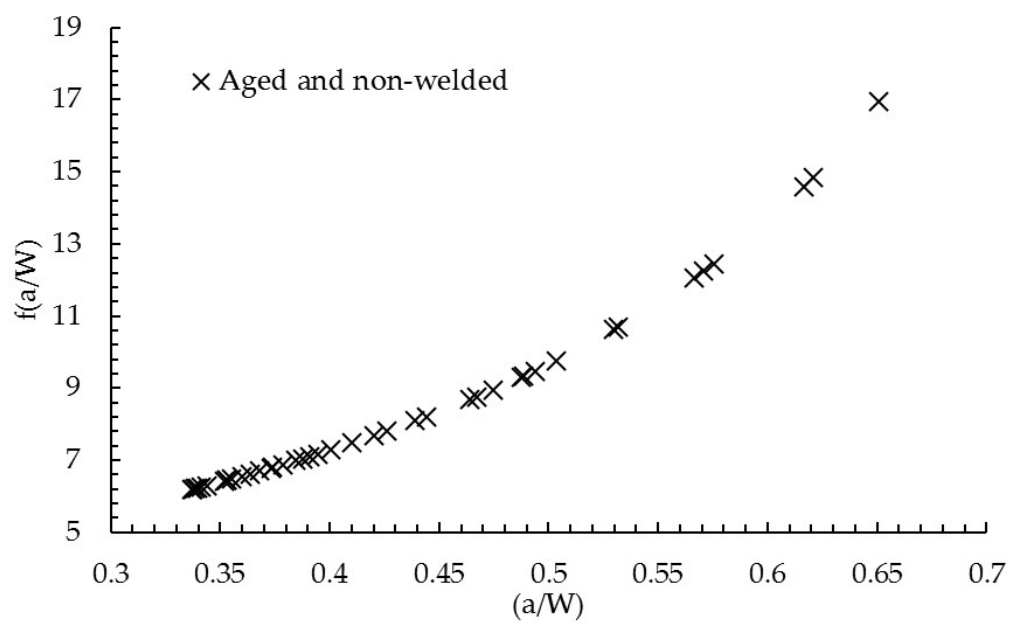

Fig. 3. Relation between $\mathrm{f}(\mathrm{a} / \mathrm{w})$ and $\mathrm{a} / \mathrm{w}$ for non-welded $\mathrm{CT}$ specimen after aging 


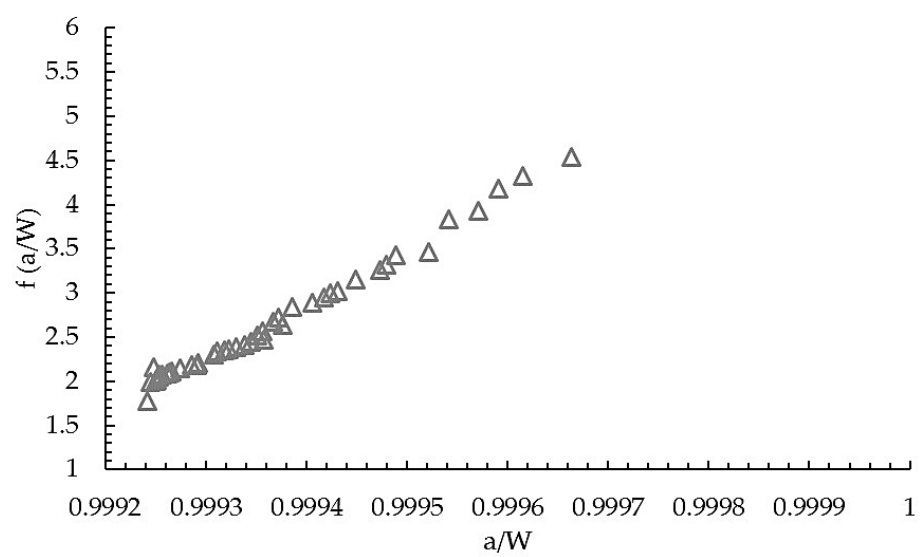

Fig. 4. Relation between $\mathrm{f}(\mathrm{a} / \mathrm{w})$ and $\mathrm{a} / \mathrm{w}$ for welded $\mathrm{CT}$ specimen after natural aging

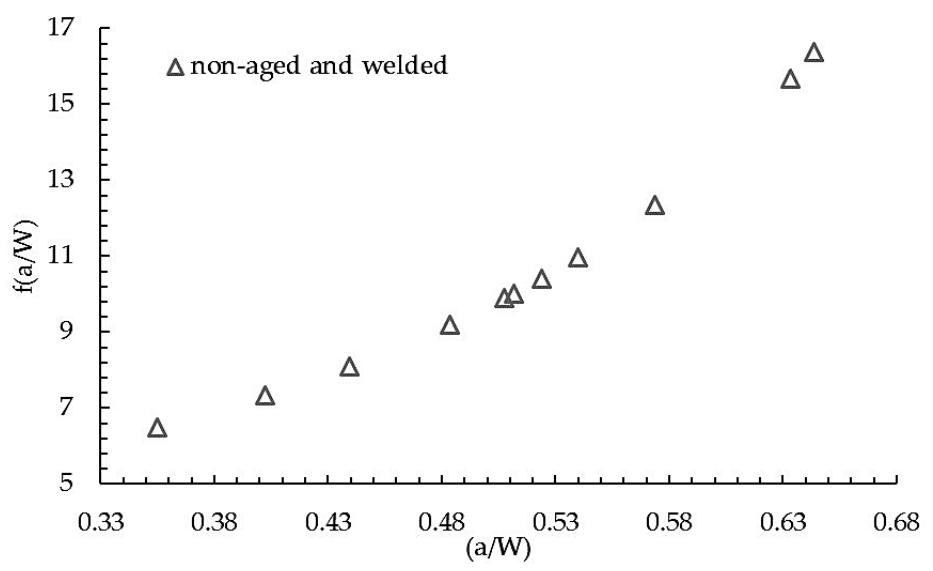

Fig. 5. Relation between $\mathrm{f}(\mathrm{a} / \mathrm{w})$ and $\mathrm{a} / \mathrm{w}$ for welded $\mathrm{CT}$ specimen before aging

\section{Dependence of $\Delta \mathrm{K}$ on "a/W" before and after aging}

\section{Base Metal}

The values of the stress intensity factor are calculated for both the welded and non-welded specimens. Critical stress intensity factor shows a clear dependence on the crack length to width ratio a/W as shown in Fig. 6. The dependence ratio is in the range of $0.333<\mathrm{a} / \mathrm{W}<0.347$ which is in the limit of ASTM general standards recommendations, $0.3<\mathrm{a} / \mathrm{W}<0.6[34]$. The dependence curve of $\mathrm{Kq}$ has a larger slope from 0.333 to 0.338 . However, the slope of the curve is relatively low from 0.338 to 0.347 . The dependence of critical stress intensity factor increases as the "a/W" value increases.

The dependence of critical stress intensity factor on propagating crack length to specimen width ratio is more prominent in aged samples, as shown in Fig. 7. It is observed from Fig. 7 that critical stress intensity factor is more homogeneous after aging and no kink in the middle of the curve is present.

\section{Weld Nugget Zone}

As discussed earlier that the critical stress intensity factor depends upon "a/W" so it affects the fatigue crack propagation behavior. The dependence ratio varies when the crack propagation trend changes. This effect is observed in base metal and TIG welded aluminum alloy. It is also mentioned in the literature that $\mathrm{Kq}$ also depends on the thickness of the specimen but in this research, the thickness value is kept constant for both, the welded and non-welded specimens so that results are comparable with each other. The relation between critical stress intensity factor and ratio between crack lengths to specimen width is shown in Fig 8. The dependence of stress intensity factor on "a/W" is same from $0.35<\mathrm{a} / \mathrm{W}<0.47$ but slightly increases after 0.47 . Most of the values 


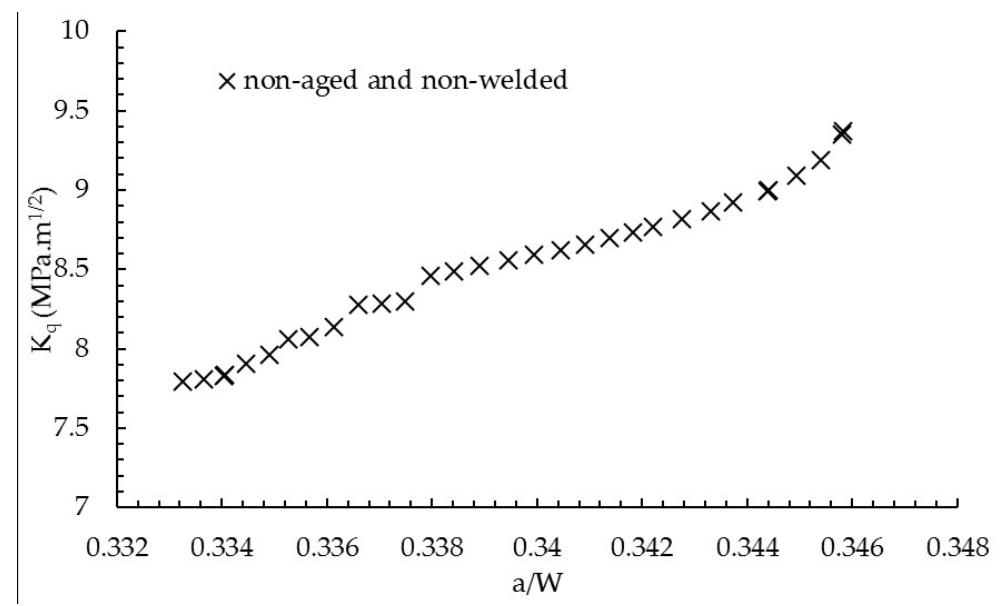

Fig. 6. Kq dependence on "a/w" for non-welded specimens

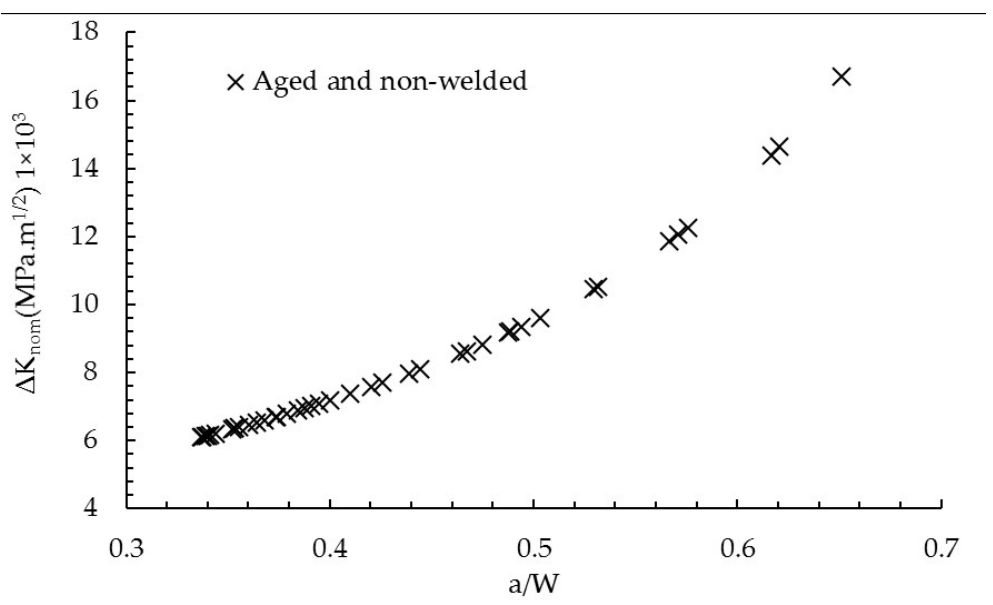

Fig. 7. $\Delta \mathrm{K}$ nom dependence on "a/w" for non-welded specimens after aging

are in the range between $0.3<\mathrm{a} / \mathrm{W}<0.6$ as recommended by ASTM standards, however, some data scatter is observed. The $\mathrm{a} / \mathrm{W}$ range on which $\mathrm{Kq}$ depends for welded metal is higher than the un-welded metal as can be seen in Fig. 9.

\section{Paris Curve before $\&$ after aging}

\section{Base metal}

Paris curves for welded and non-welded samples are plotted from optical and machine data in Fig. 10 and Fig. 12. Cracks initiate after many cycles as is depicted in the presented Paris curve formed from machine data. For design purpose, the Paris curve obtained from optical data is more reliable instead of machine data [35].

As Aluminum is a soft metal as compared to steel and other ferrous metals, so we are unable to obtain its endurance limit. This softness of the tested alloy and the alloy composition of as received aluminum plates show a peculiar behavior after the aging process in non-welded cases as seen in Fig. 11. The crack initiation regime is around $6 \mathrm{MPa} \cdot \mathrm{m}^{1 / 2}$. The crack propagates uniformly in the stress intensity regime of $8-15 \mathrm{MPa} \cdot \mathrm{m}^{1 / 2}$. The test was stopped at $15 \mathrm{MPa} \cdot \mathrm{m}^{1 / 2}$ due to instable crack growth in this regime.

\section{Weld Nugget Zone}

After TIG welding there are some internal structural changes are taken place in the metal. The positive point is that the mismatching between optical and MTS-810 data is near about zero as compared to the base metal. The fatigue failure of base metal is completely ductile type, as the specimen is not completely parted off during the test. While the failure of welded aluminum alloy is totally brittle nature as the specimens are parted off with opposite machine clevis. The results are shown in Figure 12.

The Paris curve of the weld nugget zone after aging is presented in Figure 13. It is observed that the fatigue life of the WNZ largely increases after the aging. 


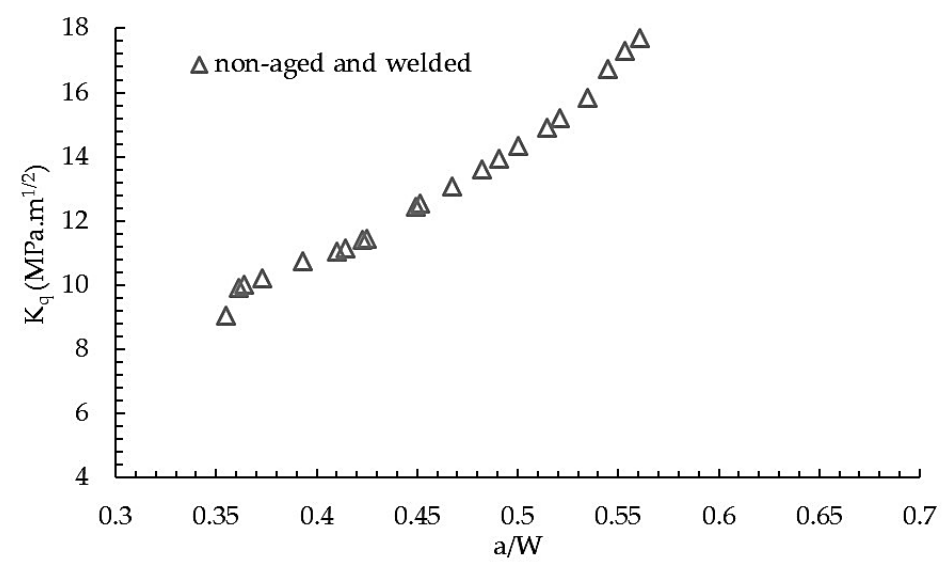

Fig. 8. $K_{q}$ dependence on " $a / w$ " for welded specimens

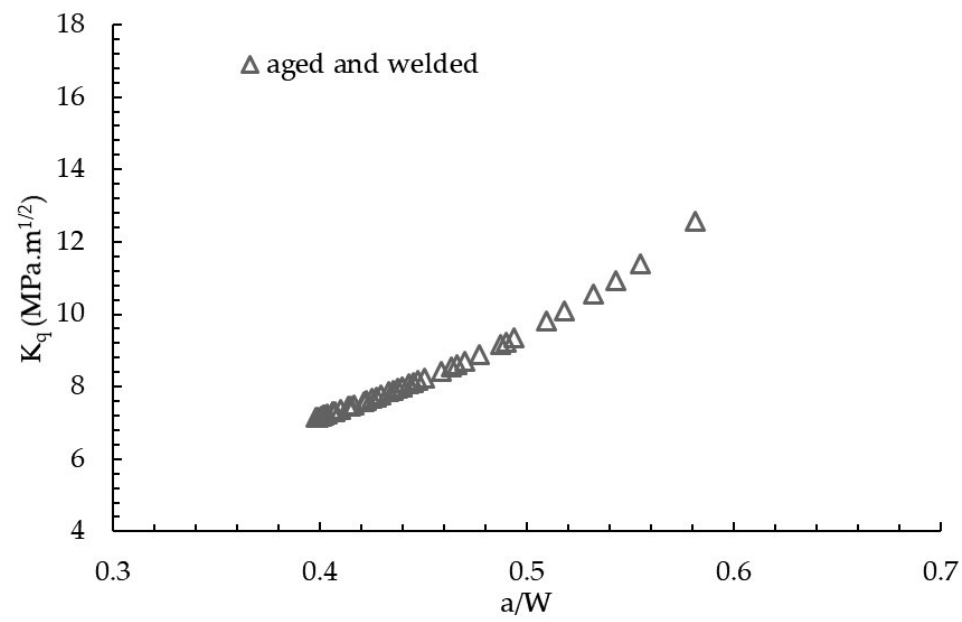

Fig. 9. $\Delta \mathrm{K}_{\text {nom }}$ dependence on " $\mathrm{a} / \mathrm{w}$ " for welded specimens

\section{Microstructure before Aging}

\section{Base Metal (BM)}

Before the welding, AA2219 is a solution type solid in which the main constituent $\mathrm{Cu}$ atoms remain dissolve in the lattice structure of $\alpha-\mathrm{Al}$ to form the monophasic structure which is clear in the Fig. 14 of the aluminum-copper phase diagram.

Because of the effect of heat treatment (T-87) of AA2219 base metal, the intermetallic structure of $\mathrm{Al} 2 \mathrm{Cu}$, which is $53.1 \%$ by weight and having an irregular geometry, are already present in the micro grain structure as shown in Fig. 14. From the microstructure of base metal as shown in Fig. 14, the grain is rolled and extended. The presence of second phase particles $(\mathrm{Al} 2 \mathrm{Cu})$ can also be seen within the grains and along the grain boundaries [36]. The precipitate free zone (PFZ), which rarely appears in the structure, can also be seen in this Figure. The intermetallic can clearly be viewed in the micro grain structure which supports the fact that some sort of aging is already been done on the base metal before welding is being performed. Due to that aging, precipitate hardening has been done on the surface of base metal whereas grain boundaries defects can clearly be seen in Fig. 14 as well. These defects are introduced due to the voids and porosities which is the best subsidiary places for stress corrosion cracking (SSC) [9].

\section{Heat Affected Zone (HAZ)}

The zone between the BM and WNZ is the heat affected zone (HAZ). Due to the higher temperature of the welding process, the mechanical changes take place abruptly in this zone, but the molten pool of weld metal is not formed as in the case of weld nugget zone. During the welding process, a supersaturated solution of molten metal us formed near the welding torch. With the passage of time, the temperature of the welded specimen 


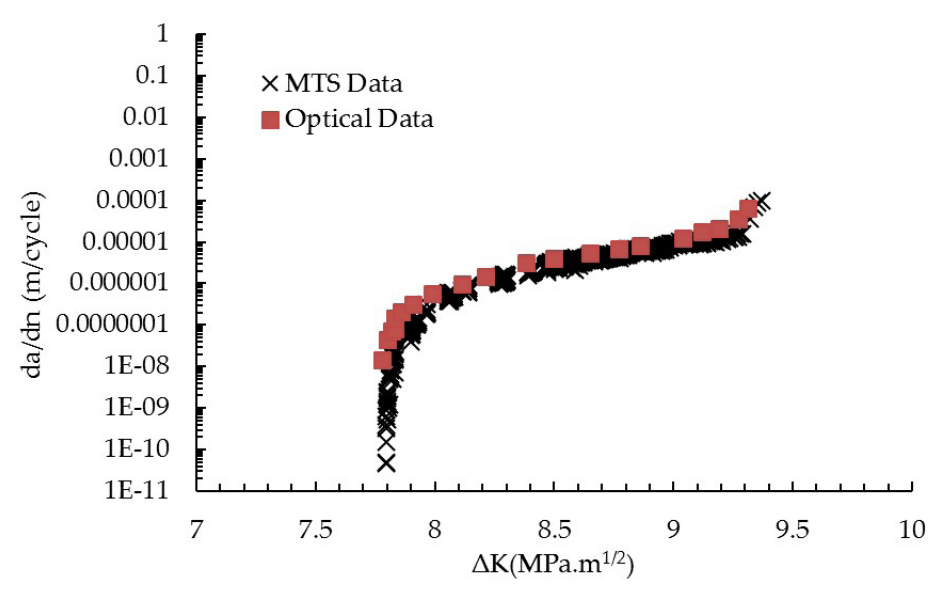

Fig. 10. Paris Curves for base metal before aging

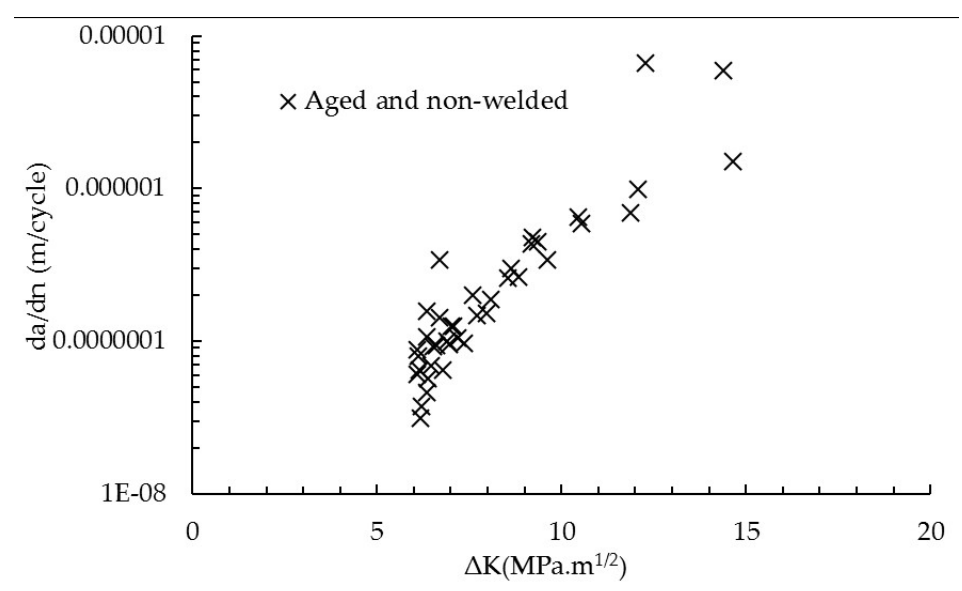

Fig. 11. Paris Curves for base metal after aging

decreases and the alloying components $(\mathrm{Cu})$ starts to rush towards the grain boundaries. As a result of this movement, a Cu-depleted $\alpha$-solid solution region is formed [37]. Due to the absence of strengthening particles i.e. intermetallic, this zone is the flimsiest zone. The detailed microstructure of HAZ is shown in Clusters of nearly the same and equal sized grain can be observed in the HAZ. This happens because of the recrystallization and Intermetallic depletion of $\mathrm{Cu}$ atoms from that zone. At some places in the microstructure, the deposition of $\mathrm{Cu}$ is found to be higher than the remaining area which accumulates on the grain boundaries of that zone. When a certain level of concentration, the grains are detached with the neighboring ones this segregation leads to the abrupt loose of mechanical properties [31].

\section{WeldNugget Zone (WNZ)}

A clear and distinct solidified dendritic structure can be observed in fusion or weld nugget zone as shown in Figure 16. Due to the high temperature of the welding process, a molten pool of metal is formed at the weld nugget zone. Due to the fast cooling and solidification of welding, a metastable stage $(\alpha+$ Liquid) is formed. This stage exists between liquid and solidus parting. Meanwhile, the second phase particles $\theta(\mathrm{Al} 2 \mathrm{Cu})$ starts to deposit around the already deposited and hardened $\alpha$-grains where the maximum solubility of the studying alloying element parallel to the solidus limit exists. The concentration of copper in both base metal (AA2219) and filler material (AA2319) is the same i.e. 6.3\%. Due to that effect, the two phases " $\theta$ " and " $\alpha$ " instantaneously separate out as the solidification temperature drop to the salvos limit. This phenomenon is basically the major cause of deterioration in mechanical properties in this zone. Due to that abrupt mechanical changes, two metastable species of second phase particles have been formed which are donated $\theta^{\prime}$ and $\theta^{\prime \prime}$. Both have the chemical composition 


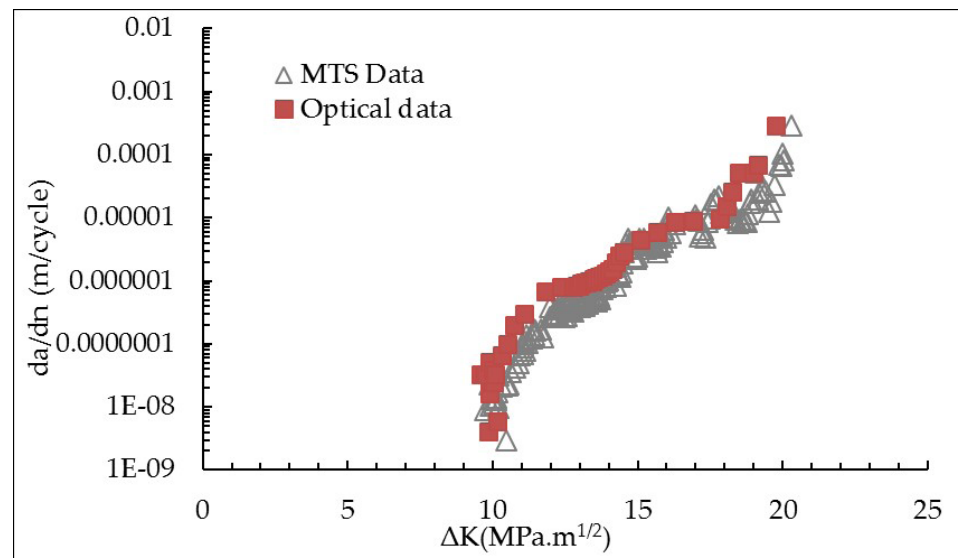

Fig.12. Paris curves for TIG welded AA2219-T87 before aging

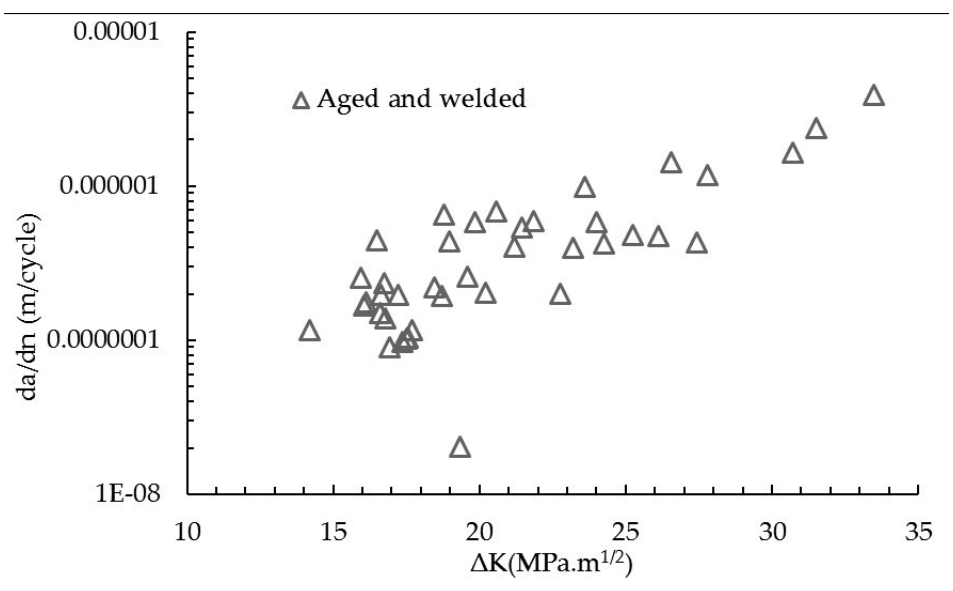

Fig. 13. Paris curves for TIG welded AA2219-T87 after aging

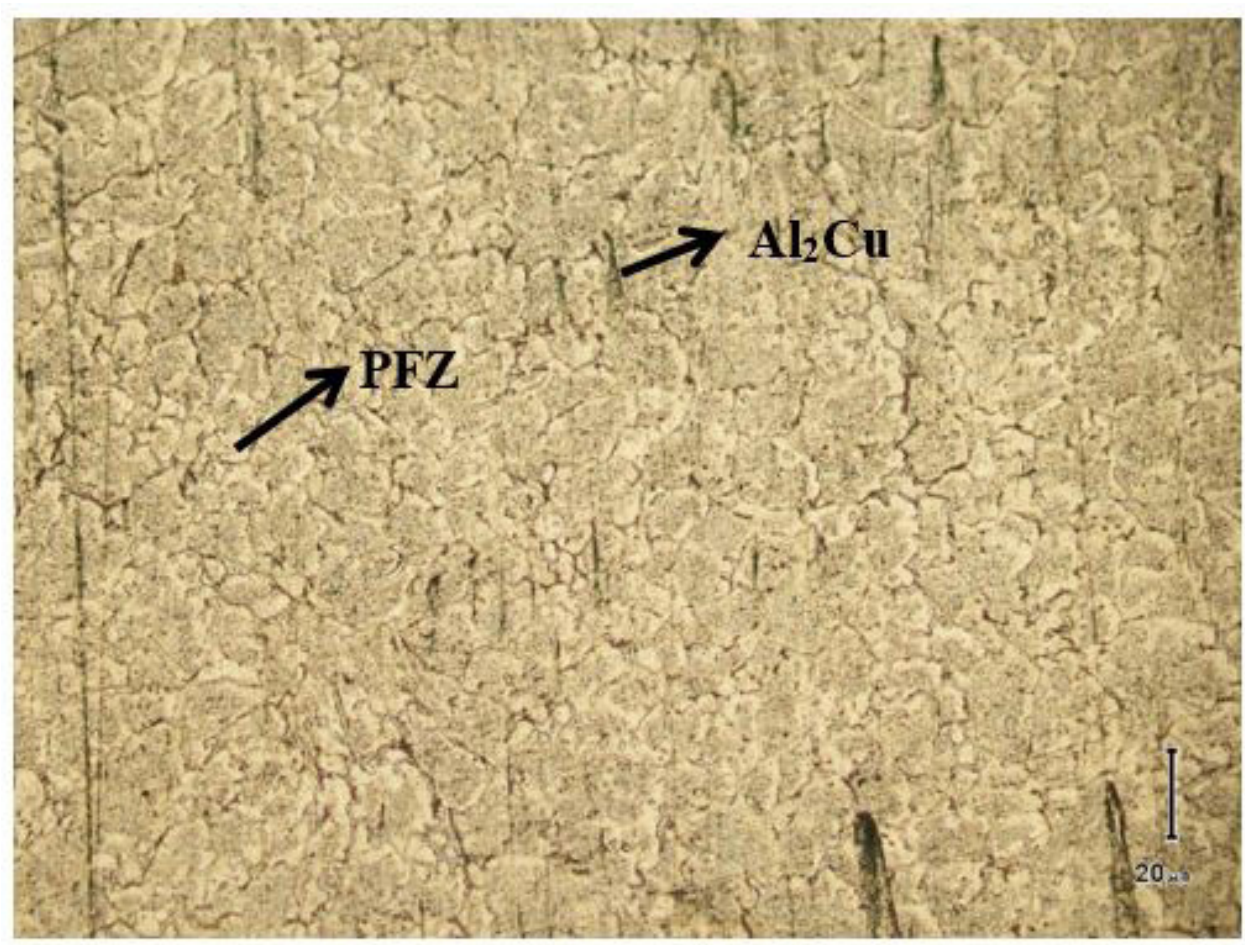

Fig. 14. Grain structure of base metal (AA2219-T87) 
of the second-phase particle $(\mathrm{A} 12 \mathrm{Cu})$. They are generated due to the successive declining of temperature[38].

The cooling has been done on room temperature which is lower than eutectic temperature. Because of this, a eutectic network forms which can be observed around the dendritic structure. In the weld nugget zone, due to the solidification, grain nucleation is always introduced which leads to dendritic structure. Because of this shrinkage and presence of entrapped gases, detachments in the dendritic arm can be clearly shown and these are responsible for the delicate zone formation in this zone. These dendritic arms also facilitate the corrosion in this zone. The researchers have found that by using the AA2319 filler alloy and TIG welding, the dendritic arm spacing (DAS) reduces considerably in WNZ.

\section{Microstructure after Aging}

\section{Base Metal}

The main difference in the metallurgy of base metal before and after aging process is the diminishing of minute pseudo, grain boundaries, which ultimately turns the incomplete grains into long, flat patched grains which are shown in Fig.17 (a). However, the base metal zone which is in the neighboring of Heat affected zone (HAZ) shows the adverse behavior as compared to the zone which is far from HAZ. They are overlapped; inter merged and partially recrystallized small sized grains as shown in Fig. 17 (b). However, from the obtained microstructure of aged material, we have found no evidence of secondary phase precipitates $(\mathrm{Al} 2 \mathrm{Cu})$, which supports the fact that the dissolution of these precipitates is not crystalized regardless of the different zones segregated in the base metal. From Figure 17 (c, d), it is clear from the aging of the zone that the grain boundaries are more vivid near the BM/HAZ boundary as compared to the BM zone which is very far from heat source. It might be possible that it's either due to the coagulation of precipitates at the pseudo boundaries or the shrinking of the peripheral area of immature grains.

\section{Heat Affected Zone (HAZ)}

The microstructure of aged HAZ is shown in Fig 18. The supersaturated solution, which is formed after the welding process at HAZ, is turned into its saturation after aging excelled due to aging. High-resolution light microscopy of grain boundaries, as shown in Fig. 18 (b), reveals that the concentration of copper can be easily judged due to light yellowish color. Copper-rich boundaries make HAZ more fragile as compared to non-aged one. This happens due to extra brittleness of the metal at aged boundaries of HAZ. Small sized grains which originate at HAZ spread a net of dense grain boundaries are responsible for intergranular crack propagation process. The excessive amount of precipitates, which were forcefully dissolved into aluminum solution, are now seen at dense grains boundaries as shown in Fig. 18 (a). The migration of $\mathrm{Cu}$, from grain's interior to boundaries, is Due to the presence of crystallographic disarrangement near foreign particles at grain boundaries, the fatigue strength of

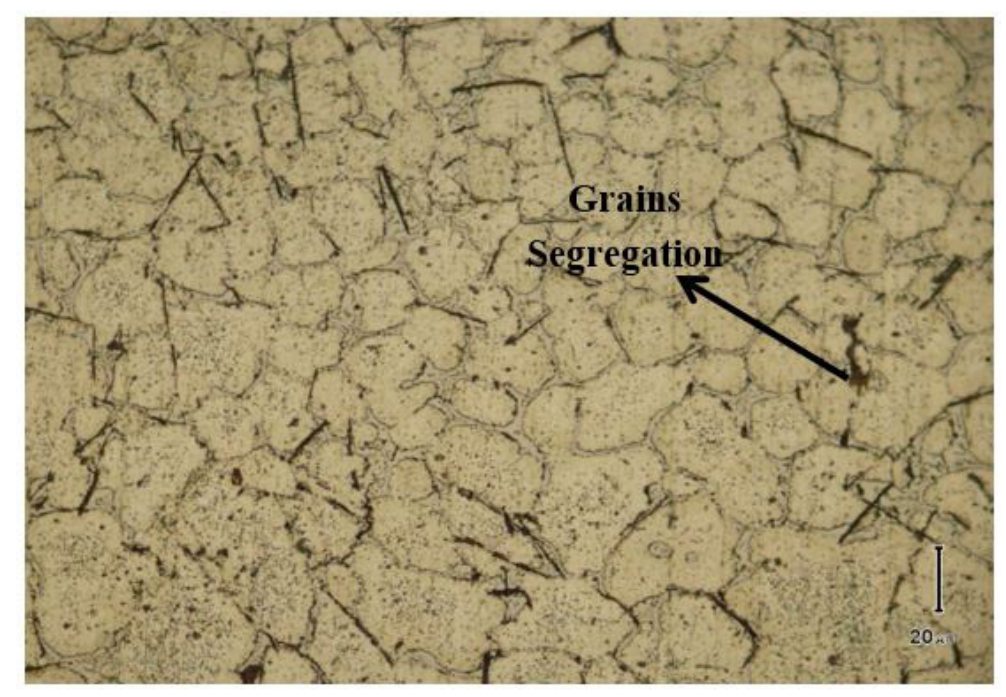

Fig. 15. HAZ of AA2319 filler welded base metal 


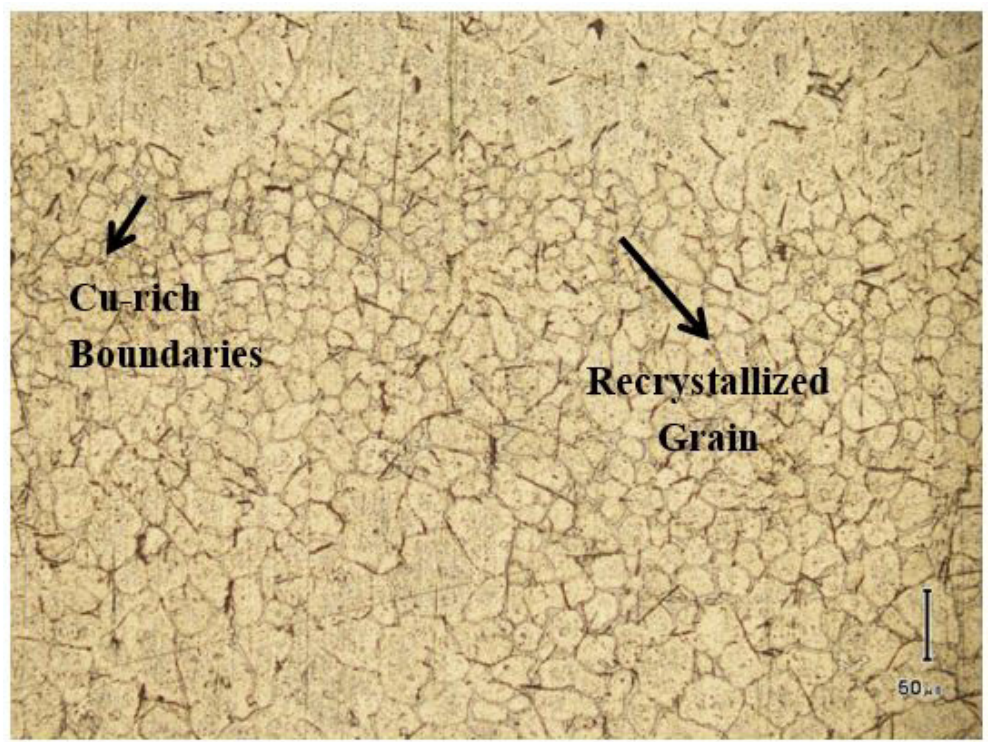

Fig. 16. Dendritic structures of WNZ (Filler AA2319)

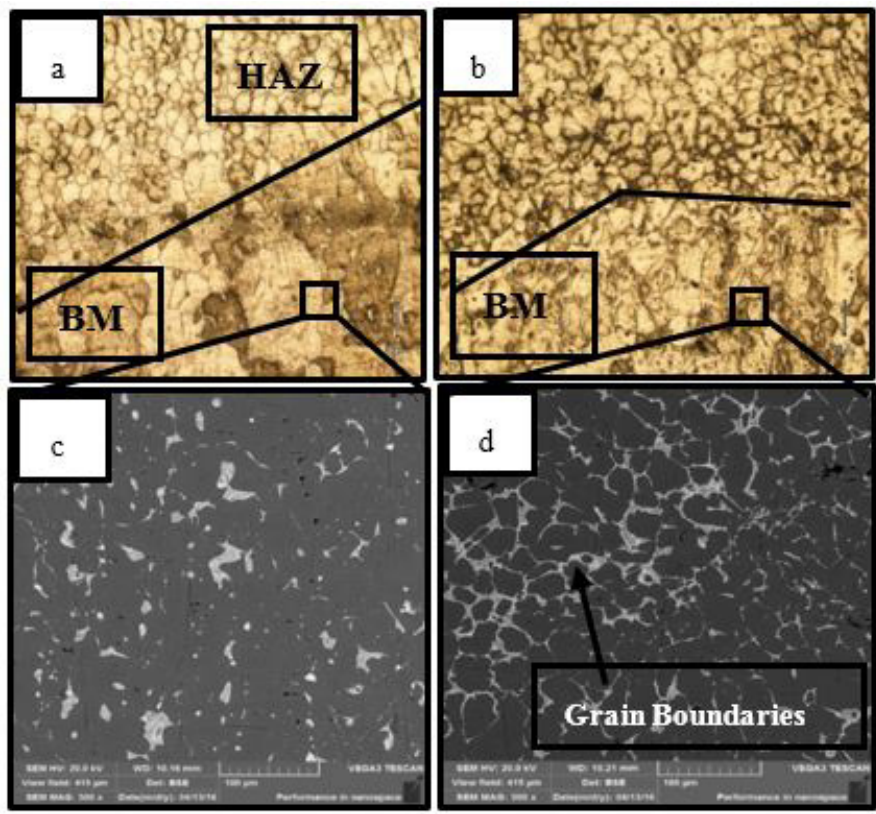

Fig. 17. The microstructure of AA2219 base metal after aging (a) long patched merged grains (b) base metal near HAZ (c) SEM of BM far from HAZ (d) SEM of BM near HAZ

this zone is very poor as compared to any other zone investigated in this research. From the fractography of the subjected zone, it is found that somewhere still secondary phase particles (enriched with $\mathrm{Cu}$ ) are detected within the grains instead of boundaries as shown in Fig. 18 (d). These seldom appearing cuprous particles within the grains are thought to be responsible for minute ductility which is shown by this zone. A comprehensive data acquisition system is also available which supports the automatic storage of captured metallographic picture.

\section{Weld Nugget Zone (WNZ)}

From the microstructure of aged weld nugget zone, it is observed that the dendritic structure, which is obtained after welding due to segregation of $\alpha$ and $\theta$ phase, has been recrystallized completely. The precipitates which are arrested due to the rapid cooling of welding started to separate 


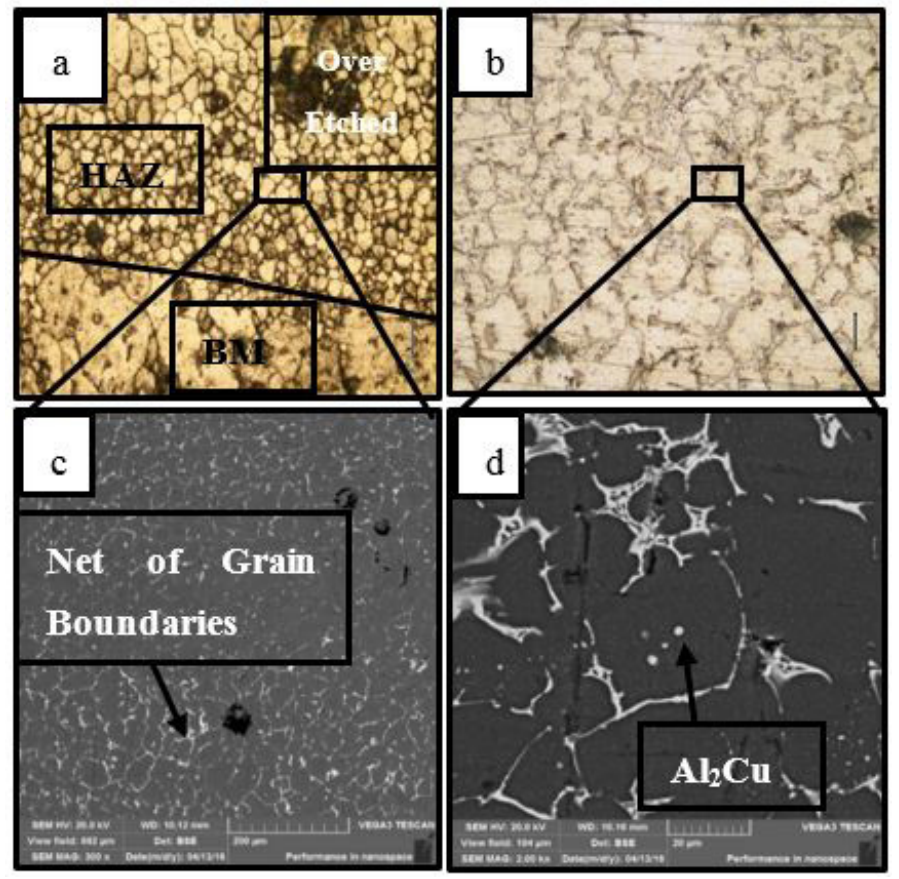

Fig. 18. Microstructure of AA2219 HAZ after aging (a) dense grain boundaries of HAZ (b) high light microscopy of grain boundaries (c) SEM of HAZ (d) Presence of secondary particle within the grain

out from plain aluminum contents. Because of this fact, proper distribution of strengthening particles become possible and this is the reason of enhancement of mechanical properties of this zone as compared to the WNZ obtained after welding. If the narrow area near the boundaries (which is still super saturated solution) is ignored, then the whole microstructure (which once stated as dendritic) is termed as mature grain as shown in Fig 19 (b). In other words, the specie which is obtained in this zone after aging, is somewhat in between the grains and dendrites. From the fractography of weld nugget zone, we also observed that after aging, the dendrite arms are merged to each other or shifted/matured to grain boundaries. This factor might be responsible for decreasing fatigue strength of this zone.

\section{DISCUSSION}

In this research, the effect of aging on fatigue life of base metal and welded Al6061 alloy has been studied. The study provides a detailed relationship between the observed fatigue life and the microstructural changes in the material before welding, after welding, after aging of base metal and after aging of the weld zone.

The nonlinear behavior in above Fig. 5 shows that the crack propagation trend is varying in TIG welded specimen during the test. As the crack propagation behavior varies then definitely the geometric correction factor also varies because it is the function of " $\mathrm{a} / \mathrm{w}$ ". This relation is calculated at " $\mathrm{H} / \mathrm{W}=1$ " of welded specimens.

The relation between $\mathrm{f}(\mathrm{a} / \mathrm{W})$ and $\mathrm{a} / \mathrm{W}$ for welded CT specimen after natural aging are shown in Fig. 4. The extra linearity of the obtained curve which is shown in Fig 4, however, in welded metal, the initial non-linearity of the curve is due to the minute variations incorporating parameters instead of the geometric factors.

The comparison of $\mathrm{K}$ dependence on $\mathrm{a} / \mathrm{w}$ is not efficiently described while considering only mechanics-based observations. Because with respect to the data plotted before and after aging of welded metal, one can only conclude that the $\mathrm{K}$ dependence is more efficiently predicted in after aging scenarios as compared to the previous ones. The comprehensive details can only be provided while considering the metallurgical approach. As the second phase precipitates, which are maturely oriented at their equilibrium sites, reinforce after aging so this is the main reason of uniform dependence of $\mathrm{K}$ on $\mathrm{a} / \mathrm{w}$ in this case as compared to non-aged metal.

From the comparison of results shown in Fig $10 \& 11$, it is concluded that after the aging process, the base metal has shown extra softness against cyclic loading. It is proposed that the data 

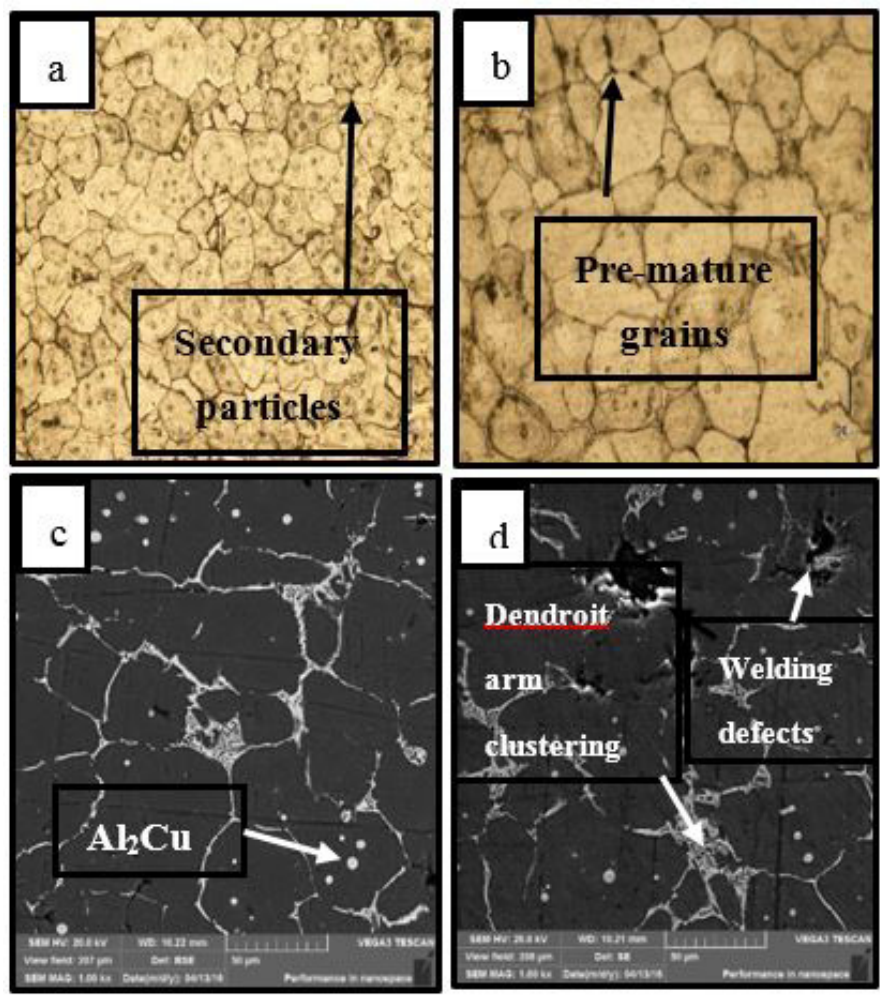

Fig. 19. The microstructure of AA2219 WNZ after aging (a) secondary particles in WNZ (b) Premature grains in WNZ (c) Al2Cu in WNZ (d) Welding defects and dendritic clusters

scattering and discussed softness is due to the disturbance of the alloy balanced percentage or some unusual chemical reaction or mechanical mixtures between the trace elements of the subjected metal.

From the comparison of the fatigue strength results of the welded aluminum before and after aging, as shown in Figures 12 and 13, it is clearly observed that after aging, the resistance against fatigue crack growth has increased enormously. The vivid reason for this behavior is the uniform distribution of second phase strengthening particles within the grain and at the grain boundaries. This hindrance in crack propagation is equally available in the case of intergranular as well as trans granular failures. There is another reason for the strengthening of aged metal is the maturing of $\mathrm{A} 12 \mathrm{Cu}$ particles which were available above the eutectic's equilibrium points. This phenomenon is responsible for the extra availability of strengthening particles per unit volume of the weld metal. Form the Fig 13, it is observed that maximum numbers of cycle are consumed in the intermediate section of the curve which shows that fatigue crack initiation and propagation becomes difficult in aged metals and this factor supports that the uniform distribution of strengthening particles is not only on the surface area which was under examination during microscopy but present three-dimensionally in the whole cross-section of the joint.

\section{CONCLUSIONS}

After the natural aging at room temperature, the specimens with the same dimensions and testing parameters have been tested again and the results were discussed and compared with the already published data without aging. These results are as under:

- Aging of the base metal zone that the grain boundaries are more vivid near the BM/HAZ boundary as compared to the BM zone which is very far from heat source. Copper-rich boundaries make HAZ more fragile as compared to non-aged one from the microstructure of aged weld nugget zone, it is observed that the dendritic structure, which is obtained after welding due to segregation of $\alpha$ and $\theta$ phase, has been recrystallized completely.

- In WNZ, we have also observed that after aging, the dendrite arms are merged with each 
other or shifted/matured to grain boundaries. This factor might be responsible for decreasing fatigue strength of this zone.

- The dependence of critical stress intensity factor on propagating crack length to specimen width ratio is more prominent in after aging results. It has been observed that critical stress intensity factor dependence is finding itself more reliable after aging as compared to before aging as there is no kink in the middle stream of the curve and the data reinforcement is in harmony as compared to the non-aged base metal. It can easily be concluded that the $\mathrm{K}$ dependence is more efficiently predicted in after aging scenarios as compared to the before aging ones.

- After natural aging process, the base metal has shown some extra softness against cyclic loading and that is due to the disturbance of alloy balanced percentage or some unusual chemical reaction or mechanical mixtures between the trace elements of the subjected metal.

- After aging, the resistance against fatigue crack growth has also increased enormously. The vivid reason for this behavior is the uniform distribution of second phase strengthening particles within the grain and at the grain boundaries. This hindrance in crack propagation is equally available in the case of intergranular as well as trans granular failures. There is another reason for strengthening of aged metal is the maturing of $\mathrm{Al}_{2} \mathrm{Cu}$ particles which were available above the eutectic's equilibrium points. This phenomenon is responsible for the availability of extra strengthening particle per unit volume of weld metal.

\section{REFERENCES}

1. Owolabi, G.M., et al., Fatigue Responses of Three AA 2000 Series Aluminum Alloys. Journal of Materials Science and Chemical Engineering, 2019. 7: p. 32-48.

2. Nijin, I., R.S. Kumar, and A. Banerjee, Role of stress-state on initiation and growth of a fatigue crack. International Journal of Fatigue, 2019. 118: p. 298-306.

3. Ullah, M., et al., Numerical Simulation and Experimental Verification of CMOD in CT Specimens of TIG Welded AA2219-T87. Arabian Journal for Science and Engineering, 2015. 40(3): p. 935-944.

4. Atta-ur-Rahman, R., et al., Demarcation of Fatigue
Crack Cumulative Damage (Initiation+ stage I) of Aluminum Alloy under Combined Loading. Life Science Journal, 2013. 10(12s).

5. Asghar, W., et al., Investigation of fatigue crack growth rate in CARALL, ARALL and GLARE. Fatigue \& Fracture of Engineering Materials \& Structures, 2017. 40(7): p. 1086-1100.

6. Mukhtar, F., et al., Effect of chrome plating and varying hardness on the fretting fatigue life of AISI D2 components. Wear, 2019. 418-419: p. 215-225.

7. Ullah, M., C.S. Wu, and F. Qayyum, Prediction of crack tip plasticity induced due to variation in solidification rate of weld pool and its effect on fatigue crack propagation rate (FCPR). Journal of Mechanical Science and Technology, 2018. 32(8): p. 3625-3635.

8. Liu, L., D. Ren, and F. Liu, A review of dissimilar welding techniques for magnesium alloys to aluminum alloys. Materials, 2014. 7(5): p. 3735-3757.

9. Malarvizhi, S. and V. Balasubramanian, Fatigue crack growth resistance of gas tungsten arc, electron beam and friction stir welded joints of AA2219 aluminium alloy. Materials \& Design, 2011. 32(3): p. $1205-1214$.

10. Malarvizhi, S. and V. Balasubramanian, Effect of welding processes on AA2219 aluminium alloy joint properties. Transactions of Nonferrous Metals Society of China, 2011. 21(5): p. 962-973.

11. Ullah, M., C.S. Wu, and M. Shah, In situ delta ferrite estimation and their effects on FCPR at different orientations of multipass shielded metal arc welded SS304L. Journal of Manufacturing Processes, 2016. 21: p. 107-123.

12. Ericsson, M. and R. Sandström, Influence of welding speed on the fatigue of friction stir welds, and comparison with MIG and TIG. International Journal of Fatigue, 2003. 25(12): p. 1379-1387.

13. Malarvizhi, S. and V. Balasubramanian, Effects of welding processes and post-weld aging treatment on fatigue behavior of AA2219 aluminium alloy joints. Journal of Materials Engineering and Performance, 2011. 20(3): p. 359-367.

14. Zhu, Z., et al., Effect of post weld heat treatment on the microstructure and corrosion behavior of AA2219 aluminum alloy joints welded by variable polarity tungsten inert gas welding. Materials \& Design (1980-2015), 2015. 65: p. 1075-1082.

15. Peng, D., et al., Effects of aging treatment and heat input on the microstructures and mechanical properties of TIG-welded 6061-T6 alloy joints. International Journal of Minerals, Metallurgy, and Materials, 2013. 20(3): p. 259-265.

16. Sharma, V.M.J., et al., Fatigue crack growth of AA2219 under different aging conditions. Materials Science and Engineering: A, 2011. 528(12): p. 4040-4049. 
17. Cao, L., P.A. Rometsch, and M.J. Couper, Clustering behaviour in an $\mathrm{Al}-\mathrm{Mg}-\mathrm{Si}-\mathrm{Cu}$ alloy during natural aging and subsequent under-aging. Materials Science and Engineering: A, 2013. 559: p. 257-261.

18. Takaki, Y., et al., Effects of Natural Aging on Bake Hardening Behavior of Al-Mg-Si Alloys with Multi-Step Aging Process. Materials Transactions, 2014. 55(8): p. 1257-1265.

19. Elahi, H., et al. Stability of piezoelectric material for suspension applications. in 2017 Fifth International Conference on Aerospace Science \& Engineering (ICASE). 2017. IEEE.

20. Swati, R., et al., Experimental and numerical investigation of transversal damage in carbon fiber reinforced composites using X-FEM analysis. Journal of Mechanical Science and Technology, 2019. 33(1): p. 205-211.

21. Memmolo, V., et al., Experimental and Numerical Investigation of PZT Response in Composite Structures with Variable Degradation Levels. Journal of Materials Engineering and Performance, 2019: p. 1-8.

22. Khan, M.U., et al., Deflection of coupled elasticityelectrostatic bimorph PVDF material: theoretical, FEM and experimental verification. Microsystem Technologies, 2018: p. 1-8.

23. Elahi, H., et al., Design and performance analysis of hybrid solar powered geyser in Islamabad, Pakistan. Therm Sci, 2018.

24. Elahi, H., M. Eugeni, and P. Gaudenzi, Design and performance evaluation of a piezoelectric aeroelastic energy harvester based on the limit cycle oscillation phenomenon. Acta Astronautica, 2019. 157: p. 233-240.

25. Elahi, H., M. Eugeni, and P. Gaudenzi, A review on mechanisms for piezoelectric-based energy harvesters. Energies, 2018. 11(7): p. 1850.

26. Elahi, H., M. Eugeni, and P. Gaudenzi, Electromechanical degradation of piezoelectric patches, in Analysis and modelling of advanced structures and smart systems. 2018, Springer. p. 35-44.

27. Swati, R., et al., Investigation of tensile and inplane shear properties of carbon fiber reinforced composites with and without piezoelectric patches for micro-crack propagation using extended finite element method. Microsystem Technologies, 2019. 25(6): p. 2361-2370.

28. Elahi, H., et al., Response of piezoelectric materials on thermomechanical shocking and electrical shocking for aerospace applications. Microsystem Technologies, 2018. 24(9): p. 3791-3798.

29. Miller, K., The behaviour of short fatigue cracks and their initiation Part I-A review of two recent books. Fatigue \& Fracture of Engineering Materials \& Structures, 1987. 10(1): p. 75-91.

30. Narayana, G.V., et al., Fracture behaviour of aluminium alloy 2219-T87 welded plates. Science and Technology of Welding \& Joining, 2004. 9(2): p. 121-130.

31. Qayyum, F., et al., Experimental Investigations and Multiscale Modeling to Study the Effect of Sulfur Content on Formability of $16 \mathrm{MnCr} 5$ Alloy Steel. steel research international, 2019.90(6): p. 1800369.

32. Newman Jr, J. and I. Raju, An empirical stressintensity factor equation for the surface crack. Engineering Fracture Mechanics, 1981. 15(1): p. 185-192.

33. Designation, A., E399-90. Standard test method for plane-strain fracture toughness of metallic materials. 1991 Annual Book of ASTM Standards, 1997. 3: p. 485-51.

34. Sultan, A., et al., Numerical simulation and experimental verification of CMOD in SENT specimen: Application on FCGR of welded tool steel. Acta Metallurgica Sinica (English Letters), 2013. 26(1): p. 92-96.

35. Hartman, J., R. Beil, and G. Hahn, Effect of copper rich regions on tensile properties of VPPA weldments of 2219-T87 aluminum. Welding Journal, 1987. 1: p. 73-83.

36. Mondolfo, L.F., Aluminum alloys: structure and properties. Vol. 5. 1976: Butterworths London.

37. Paglia, C. and R. Buchheit, Microstructure, microchemistry and environmental cracking susceptibility of friction stir welded 2219-T87. Materials Science and Engineering: A, 2006. 429(1): p. 107-114. 